\title{
ENSINO DE BIOLOGIA E REPRESENTAÇÕES SOCIAIS: UMA NARRATIVA DOCENTE
}

\section{BIOLOGY TEACHING AND SOCIAL REPRESENTATIONS: A TEACHER NARRATIVE}

\author{
SIMPLÍCIO, Paula Roberta Galvão ${ }^{1}$ \\ SANTOS, Adriana Cavalcanti dos ${ }^{2}$
}

\begin{abstract}
RESUMO
Este artigo tem por objetivo analisar a narrativa de uma professora de Biologia de um Instituto Federal sobre o processo ensino-aprendizagem dos alunos do Programa Nacional de Integração da Educação Profissional com a Educação Básica na Modalidade da Educação de Jovens e Adultos (PROEJA) na perspectiva das Representações Sociais. A referida investigação é de cunho qualitativo do tipo estudo de caso. A coleta de dados, narrativas da professora do PROEJA, deu-se por meio de uma entrevista semiestruturada, cujo corpus de análise foi tratado com base na Análise Textual Discursiva. Os resultados da pesquisa demonstram que, para a professora investigada, a articulação entre o ensino de Ciências e a contextualização do ensino pode potencializar o processo ensino-aprendizagem, construído por meio de estratégias de ensino interdisciplinares, bem como motivar os alunos para uma permanência escolar. De modo a entender como suas Representações Sociais pode influenciar diretamente em sua prática docente.
\end{abstract}

PalaVras-chave: Representações Sociais; Ensino de Ciências; PROEJA; Docente; Aprendizagem.

\begin{abstract}
This article aims to analyze the narrative of a Biology teacher from a Federal Institute about the teaching-learning process of students of the National Program for the Integration of Vocational Education with Basic Education in the Youth and Adult Education Modality (PROEJA) in perspective of the Social Representations. This research is a qualitative case study. Data collection, narratives of PROEJA's teacher, took place through a semi-structured interview, whose corpus of analysis was treated based on Discursive Textual Analysis. The research results show that, for the investigated teacher, the articulation between science teaching and teaching contextualization can potentiate the teaching-learning process, built through interdisciplinary teaching strategies, as well

1 Universidade Federal de Alagoas - UFAL. Maceió, AL, Brasil. ORCID: https://orcid.org/0000-0002-99209925. e-mail: paularoberta.gs@gmail.com

2 Universidade Federal de Alagoas - UFAL. Maceió, AL, Brasil. ORCID: https://orcid.org/0000-0002-4556282X . e-mail: adricavalcanty@hotmail.com
\end{abstract}


DOI: $10.12957 / \mathrm{e}-\mathrm{mosaicos} .2021 .47651$

as motivating students to stay in school. So, understanding your Social Representations can directly influence your teaching practice.

KeYwORDS: Social Representations; Science teaching; PROEJA; Teacher; learning.

\section{INTRODUÇÃO}

Em meio à sociedade contemporânea, a interação entre os sujeitos por meio da linguagem se faz presente de maneira ativa (BAKHTIN, 1999). Na escola, essa premissa está presente de modo a estabelecer as relações sociais entre os sujeitos alunos e professores, bem como possibilitar a construção do conhecimento científico a partir da tessitura de saberes individuais e coletivos, em termo bakhtiniano. Em outras palavras, uma construção de conhecimentos que se estabelece na relação eu-outro. Nesse sentido, para Bakhtin (1999), não é possível pensar as relações sociais humanas distante da relação do sujeito com o outro, à medida que o sujeito só se constitui no processo de interação verbal pela linguagem.

A interação social professor-aluno também se coloca como uma grande aliada no processo de (des)construção das Representações Sociais (RS) (MOSCOVICI, 2015) do professor sobre: Quem são? O que pensam? E como aprendem sobre os sujeitos da escola? E em especial, na modalidade da Educação de Jovens e Adultos (EJA)?

Considerando, no processo de interação social, a relação entre a linguagem, a vida e as práticas sociais, os sujeitos alunos da EJA trazem para os contextos de aula saberes/conhecimentos de mundo inerentes à sua vivência. Esses saberes, se potencializados na escola, podem proporcionar de forma mais significativa a construção do conhecimento científico.

Dado o exposto, a investigação ${ }^{3}$ problematiza: Quais Representações Sociais revelam as narrativas ${ }^{4}$ de uma professora de Biologia de um Instituto Federal sobre 0 processo ensino-aprendizagem dos seus alunos do PROEJA? Com base nessa problematização, o presente artigo objetiva analisar a narrativa de uma professora de Biologia sobre o processo ensino-aprendizagem dos seus alunos do PROEJA na perspectiva das Representações Sociais. Nessa direção, a tessitura do referido artigo, parte do princípio de que os discursos e crenças dos sujeitos, sejam professores e/ou alunos, provêm de muitos outros discursos e representações, não se trata apenas de uma

3 Esse estudo é parte de uma investigação em andamento de Mestrado Profissional, com a aprovação do CEP sob n 2.304.187, em 28 de setembro de 2017.

4 Entendemos como narrativa la cualidad estructurada de la experiencia entendida y vista como un relato; por otro (como enfoque de investigación), las pautas y formas de construir sentido, a partir de acciones temporales personales, por medio de la descripción y análisis de los datos biográficos (BOLIVAR, 2002, p. 5). 
DOI: $10.12957 / \mathrm{e}-\mathrm{mosaicos} .2021 .47651$

questão de palavras, mas também de imagens mentais, crenças ou preconcepções (MOSCOVICI, 2015).

A investigação, com base na abordagem teórico-metodológica da Teoria das Representações Sociais (MOSCOVICI, 2015) teve sua gênese a partir da necessidade de se repensar, no ensino de Biologia, a articulação entre os saberes científicos e os saberes das práticas sociais, constituídos por crenças, experiências e explicações sobre o objeto estudado. Esses saberes são, de certo modo, constituídos por RS.

As Representações Sociais estão diretamente relacionadas aos processos cognitivos e às práticas sociais dos sujeitos (MOSCOVICI, 2015). Destarte, em contextos escolares, conhecer e compreender as RS, desveladas por meio das percepções dos sujeitos professores e/ou alunos, a partir das atribuições de sentidos e significados (BAKHTIN, 1999) aos objetos estudados. As atitudes e expectativas geradas e validadas pelos saberes do senso comum colocam-se como aliadas à aprendizagem dos conhecimentos científicos.

A presente pesquisa, com aprovação pelo Comitê de Ética e Pesquisa (CEP) sob $n^{0}$ 2.304.187, em 28 setembro de 2017, é de natureza qualitativa (LUDKE; ANDRÉ, 2014), do tipo estudo de caso (YIN, 2010). A coleta de dados, narrativas da professora do PROEJA, deu-se por meio de uma entrevista semiestruturada. A análise dos dados, baseou-se na Análise Textual Discursiva que se configura na análise das falas dos sujeitos, fragmentadas em categorias de análise como modos de focalizar o todo por meio das partes, que tem como desafio o diálogo entre as partes, ficando atento às perspectivas dos participantes. $O$ processo de análise textual se volta à produção do metatexto, a partir da unitarização e categorização (MORAES; GALIAZZI, 2013).

Nesse sentido, foram construídas categorias de análises a partir da fala da professora, após a sua transcrição e desmontagem, mediante uma análise crítica e cautelosa que permitiu surgir o novo emergente que foi estruturado nas seguintes categorias de análise: Representações Sociais na formação docente para atuação no PROEJA, dificuldades e potencialidades dos alunos do PROEJA, Representações Sociais, interdisciplinaridade e aprendizagem. Estas foram fundamentadas conforme a fala da professora pesquisada.

Os alunos do Programa Nacional de Integração da Educação Profissional com a Educação Básica na Modalidade da Educação de Jovens e Adultos (PROEJA) têm suas trajetórias de vida e de escolarização marcadas por lutas e anseios para com suas aprendizagens, que podem ser evidenciados pela analogia à vida e, historicamente, à falta de acesso à escola. Mas que, por distintos motivos, ensejam o retorno à escola, para então emergir com o processo de escolarização possibilidades na área do conhecimento e na formação profissional (SIMPLÍCIO; SANTOS, 2018).

Considerando que o PROEJA articula o Ensino Médio com o Ensino Técnico Profissional na modalidade EJA, em sua especificidade e nesse sentido, os sujeitos alunos 
DOI: $10.12957 / \mathrm{e}-\mathrm{mosaicos} .2021 .47651$

podem expor, na interação com o professor e com os colegas da turma, suas vivências e aprendizagens. Assim o professor, com o propósito de integrar ao currículo diferentes significações a partir da perspectiva de vida do sujeito, reconhece, de certo modo, a relevância de se conhecer as RS desses sujeitos de aprendizagens.

Com foco nas RS da narrativa da professora de Biologia do PROEJA, o texto se constrói na tessitura de três seções. A primeira discute a confluência entre a Teoria das Representações Sociais e o PROEJA; a segunda trata do entrelaçamento entre o ensino de Ciências e as Representações Sociais dos sujeitos; a terceira aborda as Representações Sociais de uma professora do PROEJA sobre o processo ensino-aprendizagem. E, por fim, são tecidas as considerações finais.

\section{A TeORIa das Representações Sociais e o PROEJA: UM diálogo POSSÍvel}

O encontro entre as duas grandes categorias, Teoria das Representações Sociais (MOSCOVICI, 2015) e os saberes revelados pelos alunos do PROEJA, proporciona múltiplos olhares na busca pela perspectiva da interação e do dialogismo ${ }^{5}$ para a construção do conhecimento sobre o componente curricular Biologia. Nesse sentido, alunos e professores constroem o contexto de interação e dialogismo real por meio da linguagem verbal como sendo fundamental para o processo de (res)significação de conhecimentos científicos na escola. Segundo Bakhtin, "o centro de gravidade da língua não reside na conformidade à norma da forma utilizada, mas na nova significação que essa forma adquire no contexto" (BAKHTIN,1999, p. 92).

As Representações Sociais são "uma maneira de interpretar o cotidiano - uma forma de conhecimento social" (MOSCOVICI, 1981, p. 181) e também, "um conjunto de conceitos, proposições e explicações que se originam na vida diária no processo das comunicações interpessoais", (MOSCOVICI, 1981, p. 186). Depreende-se que muitos saberes sociais e práticas humanas advém do conhecimento popular, principalmente aqueles voltados para o ensino de Ciências. $O$ reconhecimento dos saberes sociais (YOUNG, 2007), se potencializados na escola, podem apresentar significações para a aprendizagem do conhecimento científico, de modo que trazem um viés diferenciado para o processo educativo dos sujeitos.

Para Jodelet (2001) as Representações Sociais são, de certo modo, orientações para as ações dos sujeitos em suas relações sociais com o mundo e com os outros. Desse modo, os saberes empíricos dos alunos estão arraigados pela cultura e pela inserção do

5"Observa-se, sob esse enfoque, que as relações dialógicas são apreendidas discursivamente, na língua enquanto fenômeno integral concreto, sem que se desconsidere as relações lógicas. Logo, a tensão entre relações dialógicas e lógicas indica que a linguagem somente tem vida na comunicação dialógica, comunicação de sentidos, que constitui o seu campo de existência" (FANTI, 2003, p. 98). 
DOI: $10.12957 / \mathrm{e}-\mathrm{mosaicos} .2021 .47651$

sujeito no meio social, trazendo uma hipótese epistemológica sobre a gênese dos conhecimentos científicos a ser compreendidos no âmbito escolar.

O reconhecimento dos saberes sociais no processo de aprendizagem do conhecimento científico, conhecimento poderoso ${ }^{6}$ (YOUNG, 2007) pode causar efeitos favoráveis para o processo ensino-aprendizagem, especialmente em relação aos sujeitos do PROEJA. Estes saberes sociais, como já referidos, podem ser problematizados em sala de aula pelos professores para que sejam (res)significados.

Conforme Martins "o fenômeno das representações está ligado aos processos sociais e como os indivíduos e os diferentes grupos projetam na sociedade suas percepções de homem, mundo e sociedade" (MARTINS, 2014, p. 27). Desta forma, faz-se necessário o conhecimento dos saberes dos alunos do PROEJA, provenientes de suas RS, no processo de articulação entre o Ensino Médio e o Ensino Técnico Profissional. Segundo Moscovici,

Quando estudamos representações sociais nós estudamos o ser humano, enquanto ele faz perguntas e procura respostas ou pensa e não enquanto ele processa informação, ou se comporta. Mais precisamente, enquanto seu objetivo não é comportar-se, mas compreender (MOSCOVICI, 2015, p. 43).

No contexto escolar, é preciso pensar a formação humana de uma sociedade que permite ao sujeito a exposição de seus pensamentos e seus saberes para a construção de novos conhecimentos, pois a busca por explicações para os questionamentos humanos é incessante, à medida que as inquietações e as indagações movem a construção da aprendizagem.

Em se pensando a formação para humanização, Freire (2016, p. 32) questiona: "por que não estabelecer uma 'intimidade' entre os saberes curriculares fundamentais aos alunos e a experiência social que eles têm como indivíduos?" A resposta a esse questionamento, torna-se fundamental no PROEJA, considerando que os alunos desse Programa apresentam um vasto conhecimento de mundo (FREIRE, 2016), principalmente, sobre os saberes de Ciências.

A linguagem e os símbolos como forma de comunicação social, de interação e de interpretação de fenômenos estão ligados aos interesses humanos. Desse modo, a sala de aula deve se constituir em um espaço de diálogo (BAKHTIN, 1999), de partilha de saberes e de construção de novos conhecimentos científicos.

6 "É esse conhecimento independente de contexto que é, pelo menos potencialmente, adquirido na escola e é a ele que me refiro como conhecimento poderoso" (YOUNG, 2007, p. 1296). 
DOI: $10.12957 / \mathrm{e}-\mathrm{mosaicos} .2021 .47651$

É por meio das relações e interações linguísticas na sociedade que os sujeitos tecem suas próprias conclusões a respeito de determinado conceito/conhecimento como fonte de explicação para a sua própria mente. Dessa forma, no PROEJA, sujeitos se demonstram curiosos e em busca "de novos" conhecimentos, principalmente, voltados para a formação profissional.

Com a globalização e a crescente demanda tecnológica é preciso qualificar os sujeitos para que adentrem no mercado de trabalho. Essa qualificação para a atuação prática necessita, cada vez mais, de sujeitos pensantes e críticos. Vale salientar que a oportunidade de profissionalização para aqueles sujeitos pertencentes à EJA na modalidade de educação integrada é algo que desponta novas perspectivas aos diversos grupos de alunos. Entendendo que os sujeitos do PROEJA demonstram saberes inerentes ao seu modo de vida e seus valores construídos ao longo do tempo tornando-se diferentes de alunos do Ensino Médio regular, em que apresentam uma vivência bem menor, embora, apresentem suas percepções, pois os alunos não chegam "vazios" em uma sala de aula, precisam ser moldados (SIMPLÍCIO; SANTOS, 2018).

Moscovici (2015, p. 79) afirma que "a teoria das Representações Sociais, por outro lado, toma, como ponto de partida, a diversidade dos indivíduos, atitudes e fenômenos, em toda sua estranheza e imprevisibilidade". Desse modo, investigar as Representações Sociais dos sujeitos do PROEJA é uma possibilidade também de reconhecer a diversidade de culturas, de idades e, sobretudo, de pensamentos e perspectivas expressas em contextos que perfazem a busca por aprendizagem, não importando idade tão pouco diferenças de gênero, cultura, entre outros.

As Representações Sociais dos sujeitos se entrelaçam com a comunicação e a imagem, em que uma depende da outra para a significação da hermenêutica cognitiva, pois, a partir da linguagem, elas (as Representações Sociais) se ressignificam por meio da aprendizagem.

A integração curricular apresenta diversidade em compor diferentes perspectivas na função de integrar o social, o pessoal, o profissional, o cotidiano e a experiência e, dessa maneira, constituir o conhecimento do sujeito em detrimento de uma aprendizagem potencializada.

O encontro entre a Teoria das Representações Sociais e o PROEJA, em uma linha contemporânea, traz a possibilidade de resgatar as memórias dos sujeitos sobre os mais variados saberes que são construídos ao longo de sua vivência, para uma aproximação com os conceitos científicos. Essa aproximação pode motivar os sujeitos-alunos como vozes ativas dentro da escola e da sociedade, em um viés que efetiva sua identidade e possibilita a construção do conhecimento, através da compreensão e do processo de aprendizagem significativa (MOREIRA, 2012), o que pode minimizar problemas na apropriação do conhecimento, no processo educativo e formativo do sujeito. 
DOI: $10.12957 /$ e-mosaicos.2021.47651

\section{ENTRELAÇAMENTO ENTRE AS REPRESENTAÇões SOCIAIS dOS SUJEITOS E O ENSINO DE CIÊNCIAS: IMPLICAÇÕES NO CURRÍCULO}

É dessa maneira que a prática no sentido das vivências dos sujeitos pode ser aplicada "no âmbito do processo educativo que mais íntima se afirma a relação entre teoria e a prática. Essencialmente, a educação é uma prática, mas uma prática intencionada pela teoria" (MARANDINO, et al., 2009, p. 15). A articulação entre teoria e prática é imprescindível no processo de formação de sujeitos autônomos e principalmente no que concerne às aproximações entre as Representações Sociais e o conhecimento científico, de forma que a contextualização curricular aconteça e os sujeitos possam vivenciar o observatório da teoria.

De tal maneira que as abordagens curriculares em sala de aula podem assumir estratégias didáticas diferenciadas no PROEJA. Sendo assim, ressaltar e considerar no processo de ensino-aprendizagem as narrativas dos sujeitos, trazendo estes, como participantes no processo ensino-aprendizagem e não apenas como meros depósitos de informações complexas que não fazem sentido para a sua vida social. Sobre a forma de ensinar Pozo e Crespo explicitam que,

[...] não existem "boas" ou "más" formas de ensinar, senão formas adequadas ou não para determinadas metas e em certas condições dadas e que, portanto, cada professor - ou cada leitor - deve assumir a responsabilidade do enfoque educacional que for mais adequado à sua concepção do aprendizado da ciência (POZO; CRESPO, 2009, p. 245).

Não existe uma técnica e/ou metodologia correta para se fazer Ciência, para aprender Ciência, até porque existem distintas formas de aprendizado, diferentes tempos para que se dê a construção do conhecimento, ou seja, cada pessoa, cada aluno, tem uma forma diferenciada de aprender. Desse modo, não se pode eleger uma metodologia ou técnica como verdade absoluta para o desenvolvimento do conhecimento científico, o currículo precisa considerar o processo como um todo, assim como a particularidade dos sujeitos envolvidos.

"Se ao interpretar os sujeitos relacionam o discurso atual com discursos presentes em suas histórias de vida, a construção de significados não é idêntica para todos, ou seja, não há sentido sem interpretação" (CACHAPUZ, 2012, p. 144). Tal afirmação deixa claro que as formas como se concebe a aprendizagem se constrói em ritmos e maneiras diferentes, pois cada sujeito possui uma interpretação para algo, que torna necessário professores atuantes e capacitados para entender as concepções que permeiam 0 processo educativo. 
DOI: $10.12957 / \mathrm{e}-\mathrm{mosaicos} .2021 .47651$

O ensino de Ciências, especialmente o ensino de Biologia e suas relações com o cotidiano, deixa bem mais ampla e clara a forma de trabalho em sala de aula, de modo que aconteça a interação e relação entre aluno-aluno e aluno-professor. Ressaltando 0 grande avanço científico e tecnológico, estes também devem estar presentes no PROEJA, como fator marcante. Segundo Sasseron e Carvalho,

Emerge a necessidade de um ensino de Ciências capaz de fornecer aos alunos não somente noções e conceitos científicos, mas também é importante e preciso que os alunos possam "fazer ciência", sendo defrontados com problemas autênticos nos quais a investigação seja condição para resolvê-los (SASSERON; CARVALHO, 2008, p. 335).

Nesse pensar, a experimentação e a leitura podem ser estratégias que buscam o viés da transdisciplinaridade dentro do contexto do ensino de Ciências, trazendo conteúdos que recordam o cotidiano, assim possibilitando a aprendizagem significativa e proporcionando a contextualização de diferentes conteúdos com a natureza e o social, de forma que "a gestão diferenciada do currículo possa constituir um expediente para instruir eficazmente os alunos" (TRINDADE; COSME, 2014, p. 33), possibilitando uma formação humana e a permanência escolar.

Em linhas gerais, as Representações Sociais dos sujeitos e o ensino de Ciências se entrelaçam de tal forma que se tornam aliados no processo de ensino e aprendizagem, em que pode despontar a investigação e a curiosidade como fonte de aprendizagem constante, bem como proporcionam a participação ativa do aluno e o sentimento de constituinte do processo. Esse entrelaçamento pode ser considerado um mecanismo que promove o desenvolvimento pessoal e social, formando sujeitos autônomos e críticos, desafiando padrões que, muitas vezes, são postos pela sociedade, ou ainda assim pode ressaltar as potencialidades dos estudantes que compõem o PROEJA.

Podemos salientar o intercruzamento da construção de conexões entre os sujeitos em sua relação de pertença. Segundo Jodelet (2015), as Representações Sociais estão postas no centro de três esferas interligadas: a subjetiva, a intersubjetiva e a transubjetiva. Assim, o sujeito [a professora] está inserida em um contexto em que este, influencia diretamente nas Representações Sociais do sujeito.

Nessa perspectiva, para Jodelet (2015), a esfera da subjetividade se reporta à experiência vivida engajando o corpo, a sensibilidade e as emoções, ao lado dos saberes adquiridos ou construídos. Já a esfera da intersubjetividade concerne às trocas e às interações pelo viés das quais se forjam, no consenso ou no dissenso, representações compartilhadas nos grupos definidos. E a esfera da transubjetividade remete aos elementos reguladores das visões de mundo, das ideias e dos conhecimentos, dos valores, 
DOI: $10.12957 / \mathrm{e}-\mathrm{mosaicos} .2021 .47651$

das condutas que os indivíduos e os grupos têm em comum em razão de sua implicação em uma mesma situação material ou de uma mesma condição social.

Nesse sentido, podemos entender que as diferentes relações, experiências e identidades se entrelaçam para a composição de Representações Sociais que são transpostas em diferentes ambientes de atuação do sujeito pessoal e profissional. De tal forma que essas representações são influenciadas pela relação de pertença do sujeito. Assim, as narrativas da professora se constituem com base em seu cotidiano, suas vivências que vão tecendo significações únicas para a sua prática pedagógica no seu vínculo com os sujeitos alunos, possuindo uma aproximação marcante em relação a suas experiências, as quais irão construindo sua identidade em meio à diversidade de pertencimento a um ambiente bastante diversificado repleto de histórias, valores e crenças.

\section{Representações Sociais de uma Professora de Biologia do PROEJA}

As Representações Sociais da professora do PROEJA foram evidenciadas a partir da coleta de dados por meio da entrevista semiestruturada, onde ficou explícito seu conhecimento acerca da turma e das concepções que envolvem o ensino de Ciências contextualizado. Dessa maneira, foram construídas categorias após o tratamento dos dados com base na Análise Textual Discursiva. Vale salientar que a entrevista foi gravada em áudio e transcrita pelos autores da pesquisa com as marcações do discurso oral da professora.

\section{a) Representações Sociais na formação docente para atuação no PROEJA}

Os professores têm muito a dizer, no entanto, muitas vezes, suas vozes são silenciadas em meio as atribuições diárias, pois a profissão docente carrega uma série de afazeres que perpassam a sala de aula.

Deixar emergir, pesquisar e entender as narrativas dos professores se caracteriza como um pontapé para o sucesso do aluno e para o repensar da prática-didática docente, na medida que o professor se escuta, podendo tecer suas próprias considerações sobre a sua atuação.

Assim, os pares, nessa ocasião professores e alunos, precisam estar em uma sintonia para dispor de um processo ensino-aprendizagem focalizado em estratégias de ensino as quais permitam uma aprendizagem significativa. No que concerne às formas atrativas para os alunos no sentido de contemplar um currículo integrado, vejamos a narrativa da professora investigada: 
DOI: $10.12957 / \mathrm{e}-\mathrm{mosaicos} .2021 .47651$

Não dá possibilidade de trabalhar minuciosamente cada um dos conteúdos como a gente faz no Ensino Médio integrado, no ensino dito regular. De forma que a disciplina Biologia é vista durante 3 anos. No caso do PROEJA a disciplina é vista durante 2 semestres, então é preciso uma abordagem mais ampla sem aquela visão da especificidade, do detalhe (PROFESSORA DO PROEJA, 2017).

A narrativa da professora aponta para o entendimento de que os professores precisam planejar suas aulas de maneira que favoreça a atração e a motivação dos alunos do PROEJA, visto que esses alunos possuem um tempo menor em contato com a disciplina e que vise a "uma formação integral do cidadão autônomo e emancipado" (BARACHO; MOURA, 2010, p. 161).

Vale salientar que a professora é licenciada em Ciências Biológicas, mestre em Química e Biotecnologia. É docente há 15 anos, atuando no PROEJA há aproximadamente 8 anos.

Os professores do PROEJA, precisam ter um enfoque interdisciplinar. Conforme Baracho e Moura,

A formação dos docentes deverá ter como fonte os saberes sobre como os alunos do PROEJA aprendem. Os educandos não apenas aprendem de forma diferente, mas também aprendem melhor quando se lhes ensina utilizando seus estilos de aprendizagem predominantes. Os distintos estilos de aprendizagem requerem distintos modos de ensinar, próprios às diferenças existentes entre eles (BARACHO; MOURA, 2010, p. 176).

No contexto que os professores precisam ter como foco a aprendizagem do sujeitoaluno e como esta se constrói na tessitura da informação em seus modelos mentais, as distintas formas de ensinar, práticas curriculares, corrobora para uma educação emancipadora (FREIRE, 2016), articulada aos princípios individuais de cada sujeito.

\section{b) Dificuldades e potencialidades dos alunos do PROEJA}

Em outro momento quando perguntamos à professora sobre as potencialidades dos alunos do PROEJA, bem como uma leitura sobre a vivência desses sujeitos acerca de diferentes temáticas abordadas no ambiente escolar, a mesma narrou: 
DOI: $10.12957 /$ e-mosaicos.2021.47651

As potencialidades eu vejo muitas. Apesar dos alunos estarem afastados da sala de aula há muito tempo, muitos deles há praticamente 20 anos. Podemos ter como exemplo em relação às potencialidades, as experiências anteriores deles, as quais enriquecem e proporcionam um significado para a aula e, sobretudo, para os conteúdos ministrados. Quando falamos algo, os alunos vêm com algumas experiências que tiveram, isso é muito marcante nas turmas do PROEJA. Os alunos complementam e dão significado ao conteúdo abordado. De tal forma que quando concluímos um conteúdo e o aluno consegue enxergar aquela disciplina no seu cotidiano, na sua vida, e não apenas aquelas letrinhas no livro, é o principal (PROFESSORA DO PROEJA, 2017).

Na narrativa da professora, ela reconhece que os alunos possuem muitos saberes de senso comum e expõem suas Representações Sociais no cenário escolar. E essas precisam estar presentes em sala de aula como uma forma de contextualização do currículo com o cotidiano, bem como possibilitar que esses sujeitos alunos sejam protagonistas de sua formação e da sua construção do conhecimento. De tal forma que "as representações podem ser o produto da comunicação, mas também é verdade que, sem a representação, não haveria comunicação (MOSCOVICI, 2015, p. 22). Assim, a interconexão entre a linguagem e a comunicação na exposição das Representações Sociais pode tornar os sujeitos do PROEJA confiantes, motivados e partícipes da sua formação social, pessoal e profissional.

Em contrapartida a professora também narrou algumas dificuldades dos alunos do PROEJA, observem:

Em relação as dificuldades acredito que decorrem justamente do longo tempo afastados da sala de aula, se por um lado as experiências ajudam, o fato dos alunos estarem a um longo tempo distantes do ensino formal, também é uma dificuldade. Entendo que até eles ganharem confiança de que são capazes de continuar, que realmente estão aprendendo essa disciplina ou as outras. Então até chegar a esse ponto tem dificuldades, por exemplo, do estudante ter que fazer um cálculo, até mesmo em Biologia que alguns conteúdos a gente precisa disso e o aluno tá distante desses cálculos há 10 anos, 20 anos. Dessa forma, essas são dificuldades iniciais, o fato que os alunos estão afastados da sala de aula, por muito tempo, pelo menos uma boa parte deles (PROFESSORA DO PROEJA, 2017).

O tempo e espaço do PROEJA são ambientes diferenciados compostos por sujeitos com diversificadas identidades, crenças e valores. Porém, possuem um conjunto e características próprias como descontinuidade de estudos, reprovações, lacunas 
DOI: $10.12957 / \mathrm{e}-\mathrm{mosaicos} .2021 .47651$

cognitivas, necessidade de trabalhar para auxiliar/manter a família (BARACHO; MOURA, 2010). Características estas que diferem dos alunos do Ensino Médio regular e, a princípio, pode dificultar a aprendizagem e fortalecer a vontade de não permanecer estudando.

\section{c) Interdisciplinaridade e aprendizagem}

Nesse contexto, a disciplina de Biologia apresenta muitos conteúdos que possuem coerência com o cotidiano dos sujeitos. Sendo assim, indagamos à professora sobre qual conteúdo da disciplina de Biologia os alunos tinham dificuldade na aprendizagem, a professora narrou que:

O tema, Genética. Quando se fala em cruzamento e probabilidade, a princípio os alunos estranham essas questões, mas eu estou me surpreendendo com eles, pois os cruzamentos que eu tenho feito por meio de exercício eles têm bons resultados e têm levado para a sala de aula muitas curiosidades. Os alunos fazem comparações, como exemplo: meus pais eram assim, eu posso ter nascido desse mesmo jeito? Aquelas curiosidades normais! Uma outra coisa interessante, estamos trabalhando com fotos de familiares deles para observação. Essas fotos são para uma dinâmica em sala sobre as semelhanças entre gerações. Estas vão sendo misturadas, vamos apresentando as fotos aos poucos observando características. De qual família vocês acham que essa pessoa é? $E$, de acordo com essas similaridades, eles vão tentando identificar. Sendo um exercício diferente para trabalhar: genética atrelada ao cotidiano deles (PROFESSORA DO PROEJA, 2017).

A narrativa apresentada pela professora, demonstra que os alunos apresentam dificuldades, principalmente em relação ao tema Genética, o qual envolve pequenos cálculos, probabilidade e cruzamentos para determinar características genéticas dos indivíduos. Porém, há que se dizer que este tema causa estranheza não somente aos alunos da EJA, mas também aos alunos que compõem outras modalidade e níveis de ensino da educação básica.

Ponderamos que a fala da docente aponta para dificuldades que são comuns entre diferentes alunos, estando os professores responsáveis para remodelar essa adversidade contornando percepções e fundamentando a aprendizagem do aluno, de modo que eles percebam sentido no assunto, assim como vejam possibilidades práticas e de aplicações. seus alunos:

Ainda nesse contexto, a professora do PROEJA explica acerca da aprendizagem dos 
DOI: $10.12957 /$ e-mosaicos.2021.47651

Alguns casos são mais marcantes. A gente observa que algumas turmas que têm uma proximidade maior no nível de aprendizagem devido ao nível de escolaridade ser basicamente o mesmo, pois já concluíram o Ensino Fundamental e agora estão no Ensino Médio. Porém, devido às lacunas que foram ficando pelo tempo de afastamento da escola, você percebe uma dificuldade maior de um aluno do que em outros. Vamos trabalhando isso tentando também pontualmente auxiliar os que têm mais dificuldade. Eles são assim abertos, um colabora com o outro. Você vê muito essa interação. Às vezes um aluno pergunta e outro aluno já ajuda a responder, dessa forma é bom para relação aluno-aluno e aluno-professor, vai sanando essas dificuldades (PROFESSORA DO PROEJA, 2017).

Com base nesta narrativa percebemos que a professora tenta trabalhar de forma individualizada com os alunos, com enfoque na perspectiva da diferenciação curricular em que respeita as singularidades cognitivas e culturais dos alunos, facilitando a aprendizagem desses sujeitos (TRINDADE; COSME, 2014). E, nessa perspectiva, fazer com que esses sujeitos se sintam confortáveis em expor e sanar suas dúvidas e não vejam a escola como um ambiente de tensões, mas sim de realizações e aprendizagens. Para isso, o professor que atua como um mediador tem função importante na orientação dos alunos para um caminho que interpõe uma variedade de saberes e a interdisciplinaridade. A professora expõe sobre um projeto trabalhado no PROEJA de um Instituto Federal:

Tem uma metodologia no PROEJA que trabalha de forma interdisciplinar com o projeto "olhar diver cidade", no planejamento da aula de Biologia, já pensa também sobre qual cidade que vai ser visitada. O que é que tem lá? Pensando em fazer uma ponte no decorrer da trajetória da disciplina. Por outro lado, nós trabalhamos de forma interdisciplinar, por exemplo, Biologia e Química, planejando algo em comum e também de forma individualizada, mas voltada para cada disciplina. Trabalhamos com projetos. Normalmente, durante cada semestre, temos um projeto onde apresentamos conteúdos que se aproximam do cotidiano dos alunos, visto que estes são jovens e adultos que trazem suas experiências, mesmo que não direta em relação a disciplina em si, mas uma visão ampla de mundo, da natureza (PROFESSORA DO PROEJA, 2017).

Nesse sentido, a professora narra a importância da interdisciplinaridade em que fomenta a junção entre disciplinas e o acontecimento de um projeto, o qual interliga 0 conhecimento prático adquirido a partir de visitas técnica com o conhecimento científico.

Sendo assim, é importante reiterar que a profissão docente está em constante mudanças e na busca por conhecimentos. "Se o professor é realmente um sujeito do 
DOI: $10.12957 / \mathrm{e}-\mathrm{mosaicos} .2021 .47651$

conhecimento e o produtor de saberes, é preciso então reconhecê-lo como tal e dar-lhe um espaço nos dispositivos de pesquisa" (TARDIF, 2011, p. 238). Assim, o entrelaçamento de ações no âmbito escolar, permite entender que,

A escolarização repousa basicamente sobre interações cotidianas entre os professores e os alunos. Sem essas interações a escola não é nada mais que uma imensa concha vazia. Mas essas interações não acontecem de qualquer forma: ao contrário, elas formam raízes e se estruturam no âmbito do processo de trabalho escolar e, principalmente, do trabalho dos professores sobre e com os alunos (TARDIF; LESSARD, 2014, p. 23).

Isso posto, as interações, comunicações vão sendo construídas e moldadas no espaço escolar, onde professores e alunos são detentores de saberes e estes estão enraizados na cultura de cada sujeito o qual permite a construção de um conhecimento científico e social.

\section{CONSIDERAÇÕES}

A investigação mostrou que o PROEJA em confluência com as Representações Sociais e o ensino de Ciências pode torna-se um aliado para a prática em sala de aula, na medida que os professores podem entender como os saberes sociais são produzidos, como estes podem favorecer à construção da aprendizagem dos sujeitos, e pode proporcionar uma potencialização dos saberes apresentados aos alunos. Sendo capaz de possibilitar a esses sujeitos a participação ativa no processo de ensino aprendizagem, o que podem trazer contribuições para o conhecimento científico dos sujeitos. Assim, é relevante ressaltar que fazer emergir as Representações Sociais de sujeitos pode favorecer o processo de ensino e aprendizagem e a construção de um conhecimento científico.

Evidenciamos esse entrelaçamento na relação que se constitui entre as Representações Sociais e o PROEJA, pois essas relações sociais podem ser ressaltadas em qualquer nível ou modalidade de ensino, entretanto, neste programa, esta pode ser articulada de maneira singular considerando que esses sujeitos são constituídos de vastos saberes provenientes de suas experiências. Dessa maneira é relevante entender as Representações Sociais docentes com a finalidade de influência intrínseca em sua práticadidática, de modo que é pertinente esta percepção na medida que pode existir uma reflexão por parte da docente sobre sua atuação, intervindo diretamente na aprendizagem dos alunos.

De tal modo que é possível expor saberes enraizados na cultura de alunos e professores, (res)significando-os em uma linguagem científica, em que a compreensão 
DOI: $10.12957 / \mathrm{e}-\mathrm{mosaicos} .2021 .47651$

aconteça de fato e que o sujeito seja capaz de fazer Ciência, exercer a crítica e contribuir no meio social de forma autônoma por meio do conhecimento e a busca pelo saber.

Assim, observamos nas narrativas da professora do PROEJA a diversidade de alunos que compõem essa modalidade, os quais apresentam potencialidades e dificuldades que precisam ser postas e moldadas em sala de aula para que, dessa forma, a aprendizagem significativa transpasse o cenário escolar e esse aluno torne-se o construtor do seu conhecimento e permaneça na escola dando continuidade aos seus estudos, evidenciando a sua capacidade de aprender e de transformar a sua realidade. E, colocamos como possibilidade de visibilidade das Representações Sociais dos sujeitos para a construção e fundamentação do conhecimento. No sentido que o senso comum perpassa por diferentes saberes acerca do mundo e que trazem a hermenêutica para os modelos mentais, assim configurando um cenário de aprendizagem individual, a partir da pertença e coletividade no meio social em que é explicitado na Teoria das Representações Sociais.

Este estudo possibilita margens para indagações futuras no que concerne a entender quais as práticas pedagógicas podem ser adotadas pelos docentes, as quais considerem as Representações Sociais dos sujeitos. E ainda que permita a investigação com os sujeitos-alunos no intuito de entender as Representações Sociais sobre a práticadidática dos professores do PROEJA para a promoção de uma aprendizagem significativa. 
DOI: $10.12957 /$ e-mosaicos.2021.47651

\section{REFERÊNCIAS}

BAKHTIN, M. Marxismo e Filosofia da Linguagem. 9. ed. São Paulo: HUCITEC, 1999.

BARACHO, M. G; MOURA, D. H. (orgs.) PROEJA no IFRN: práticas pedagógicas e formação docente. Natal: IFRN Editora, 2010.

BOLIVAR, A. B. 'De nobis ipsis silemus?': epstemoligia de la investigación biográficonarrativa en educación. Revista Eletrónica de Investigación Educativa, Barcelona, v. 04, n. 1, 2002. Disponível em: < https://redie.uabc.mx/redie/article/view/49/91 > Acesso em: 28 jan. 2018.

CACHAPUZ, A. F. et al. O ensino das ciências como compromisso científico e social: os caminhos que percorremos. São Paulo: Cortez, 2012.

FANTI, M. G. C. D. A linguagem em Bakhtin: pontos e pespontos. VEREDAS - Rev. Est. Ling, Juiz de Fora, v.7, n.1 e n.2, p.95-111, jan./dez. 2003. Disponível em: <https://www.ufjf.br/revistaveredas/files/2009/12/artigo32.pdf > Acesso em: 04 jan. 2018.

FREIRE, P. Pedagogia da autonomia: saberes necessários à prática educativa. 53 ed. Rio de Janeiro: Paz e Terra, 2016.

JODELET, D. Representações sociais: um domínio em expansão. In: . (Org.). As representações sociais. Rio de Janeiro: EdUERJ, 2001. p.17-44.

JODELET, Denise. Problemáticas psicossociais da abordagem da noção de sujeito. Cadernos de Pesquisa, São Paulo, v. 45, n. 156, p. 314-327, June 2015. Disponível em: $<$ http://www.scielo.br/scielo.php? script $=$ sci arttext\&pid $=$ S010015742015000200314\&Ing=en\&nrm=iso $>$. Acesso em: 03 Dez. 2020.

LUDKE, M.; ANDRÉ, M. E. D. A. Pesquisa em educação: abordagens qualitativas. 2.ed. reimpr. - Rio de Janeiro: E.P.U, 2014.

MARANDINO, M.; et al. Ensino de biologia: histórias e práticas em diferentes espaços educativos. São Paulo: Cortez, 2009.

MARTINS, N. E. G. Representações das aulas de educação física para alunos da educação de jovens e adultos no segundo segmento e o trabalho docente. Maceió, $\mathrm{AL}, 2014$. Originalmente apresentada como dissertação de mestrado, Universidade Federal de Alagoas. 
DOI: $10.12957 / \mathrm{e}-\mathrm{mosaicos} .2021 .47651$

MORAES, R.; GALIAZZI, M. C. Análise textual discursiva. - 4.ed.- rev. reimpr.- Ijuí: Editora da Unijuí, 2013.

MOREIRA, M. A. O Que é Afinal Aprendizagem Significativa? Mato Grosso, Cuiabá, Qurriculum, La Laguna, Espanha, 2012, v. 1, p. 1-27, 2012. Disponível em: <https://www.if.ufrgs.br/ moreira/oqueeafinal.pdf > Acesso em: 26 abr. 2018.

MOSCOVICI, S. Representações sociais: investigações em psicologia social. Editado em inglês por Gerard Duveen; traduzido em inglês por Pedrinho A. Guareschi. 11. Ed.Petrópolis, RJ: Vozes, 2015.

. On social representations. In: FORGAS, J.P. (Org.). Social cognition: perspectives on everyday understanding. Londres: London Academic Press, 1981. p.181-209.

POZO, J. I.; CRESPO, M. A. G. A aprendizagem e o ensino de ciências: do conhecimento cotidiano ao conhecimento científico. - 5.ed. - Porto Alegre: Artmed, 2009.

SASSERON, L. H.; CARVALHO, A. M. P. Almejando a alfabetização científica no ensino fundamental: a proposição e a procura de indicadores no processo. Investigações em Ensino de Ciências - V13(3), pp 333-352, 2008. Disponível em: $<$ www.if.ufrgs.br/cref/ojs/index.php/ienci/article/view/445/263 > Acesso em: 28 mai. 2018.

SIMPLÍCIO, P. R. G.; SANTOS, A. C. Infecções Virais: saberes emergentes das Representações Sociais. Revista COCAR, Belém, V.12. N.24, p. 246 a 272 - Jul./Dez. 2018. Disponível em: https://paginas.uepa.br/seer/index.php/cocar/article/view/1922 > Acesso em: 18 Jan. 2019.

TARDIF, M. Saberes Docentes e Formação Profissional. 12.ed. - Petrópolis, RJ: Vozes, 2011.

TARDIF, M.; LESSARD, C. O trabalho docente: elementos para uma teoria da docência como profissão de interações humanas. 9.ed. - Petrópolis, Rj: Vozes, 2014.

TRINDADE, R.; COSME, A. A diferenciação curricular e pedagógica como um desafio epistemológico. Cadernos de pesquisa: pensamento educacional, Curitiba, v. 9, n. 23, p.21-42 set./dez. 2014. Disponível em: <https://seer.utp.br/index.php/a/article/view/342 > Acesso em: 08 set. 2018.

VIGOTSKI, L. S. A formação social da mente: o desenvolvimento dos processos psicológicos superiores. 7a ed. - São Paulo, 2007. 
DOI: $10.12957 / \mathrm{e}-\mathrm{mosaicos} .2021 .47651$

YIN, R. K. Estudo de caso: planejamento e métodos. Tradução Ana Thorell- 4. Ed.- Porto Alegre: Bookman, 2010.

YOUNG, M. Para que servem as escolas? Educação e Sociedade, Curitiba, vol. 28, n. 101, p. 1287-1302, set./dez. 2007. Disponível em: < http://www.scielo.br/pdf/es/v28n101/a0228101.pdf > Acesso em: 20 nov. 2018.

Recebido em 05 de janeiro de 2020

Aceito em $1^{\circ}$ de março de 2021

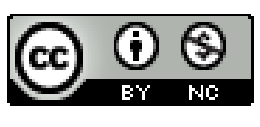

A e-Mosaicos Revista Multidisciplinar de Ensino, Pesquisa, Extensão e Cultura do Instituto de Aplicação Fernando Rodrigues da Silveira (CAp-UERJ) está disponibilizada sob uma Licença Creative Commons - Atribuição - NãoComercial 4.0 Internacional.

Os direitos autorais de todos os trabalhos publicados na revista pertencem ao(s) seu(s) autor(es) e coautor(es), com o direito de primeira publicação cedido à e-Mosaicos.

Os artigos publicados são de acesso público, de uso gratuito, com atribuição de autoria obrigatória, para aplicações de finalidade educacional e não-comercial, de acordo com o modelo de licenciamento Creative Commons adotado pela revista. 